\title{
Organic Solvent Free Process to Fabricate High Performance Silicon and Graphite Composite Anode
}

\author{
Haiqing Xiao ${ }^{\text {a, b }}$, Tianyue Zheng ${ }^{a}$, Gao Liu ${ }^{a, *}$
}

a: Lawrence Berkeley National Laboratory, 1 Cyclotron Rd, Berkeley, CA 94720, tyzheng@lbl.gov

b: Institute of Industrial and Consumer Products Safety, Chinese Academy of Inspection and Quarantine (CAIQ), No.11 Ronghua South Road, Daxing District, Beijing, 100176, China, xiaohaiqing@ @otmail.com

*Correspondence: gliu@lbl.gov

Abstract:

Cycling reliability is crucial for Si-based materials due to severe volume change during cycles that results in the fast capacity fading. Though the binder only occupies a very low amount of the total mass of anodes, it is proved to perform a key parameter to improve the cycle performance of Si-based anodes. Because they are eco-friendly and cost saving, water-based binders styrene-butadiene rubber (SBR) and carboxymethyl cellulose (CMC) are regarded as the better binder to substitute Poly (vinylidene difluoride) (PVDF) as the binder for Si-based anode. In this study, the anodes are fabricated by simply mixing the active materials (naso $\mathrm{Si}$, graphite and conductive additive) together and using the mixture of $\mathrm{SBR}$ and $\mathrm{CMC}$ as a binder. The results showed that the retention capacities of the anodes are more than $440 \mathrm{mAh} / \mathrm{g}$ after 400 cycles. It indicates that it is an easy and simple way to make high performance anodes.

Key words: Lithium-ion batteries, water-based binders, styrene-butadiene rubber (SBR), carboxymethyl cellulose (CMC), Silicon, Graphite, anode

1. Introduction

Lithium-ion batteries (LIBS) are currently being developed to power an increasingly diverse range of applications, from portable devices, such as cell phones, laptop computers, and MP3 players, to large scale equipment, including electric vehicles (EVs) and energy-storage systems (ESSs) ${ }^{[1-3]}$. A large amount of research has focused on the development of high-capacity active materials to enhance the energy density and performance of the next generation of LIBs. In particular, silicon (Si) is theoretically expected to have 10 times higher capacity (ca. $4200 \mathrm{mAh} / \mathrm{g}$ ) than that of the current graphite anode (ca. 370 $\mathrm{mAh} / \mathrm{g})^{[4-8]}$. However, the practical applications of silicon have been hindered due to severe volume change during repetitive lithiation and delithiation cycles that results in the loss of electrical contact and the fast capacity fading ${ }^{[9,10]}$. In order to solve the volume change problem, researchers have developed nanostructured Si-based anode materials and composite materials ${ }^{[11-14]}$. These Si-based materials show excellent electrochemical performance. However, their complicated preparation technologies may cause high cost and be difficult for large scale production. Another approach is to develop better polymer binders, which play a crucial role to accommodate the volume change of silicon materials though they only account for a small percentage of mass loading in the electrode matrix ${ }^{[15]}$.

Conventionally, poly (vinylidene difluoride) (PVDF) binder is widely used for Li-ion cells due to its good electrochemical stability and binding capability. However, the process using PVDF normally requires the usage of organic solvents like N-methyl-2-pyrrolidone (NMP), which is potentially hazardous and not cost efficient ${ }^{[15,16]}$. Therefore, it will be beneficial to develop binders that can be processed with less toxic, or even non-toxic solvents. Recently, it was reported that water-based binder such as styrene- 
butadiene rubber (SBR) and carboxymethyl cellulose (CMC) effectively improves the cycling stability of silicon electrode ${ }^{[15-26]}$. According to a previous report by Hochgatterer et al. ${ }^{[21]}$, the formation of a covalent chemical bond between the CMC and silicon particle plays an important role in the effective binding and improved performance. Buqa et al. ${ }^{[17]}$ and Liu et al. ${ }^{[25]}$ found that the capacity retention of Si was significantly improved by using styrene butadiene rubber (SBR) and sodium carboxymethyl cellulose (CMC) as binders. The authors noted that the addition of SBR helps to enhance the elasticity of the laminate since $C M C$ is extremely brittle. Li et.al ${ }^{[20]}$, however, showed that the Si with only CMC binder has better performance than either the SBR and CMC mixture or conventional PVDF binder. Because the SBR mixture binder show a greater adhesion strength and larger breakage elongation, it can stick to the particles and current collector to withstand a greater stress before de-bonding and to tolerate a greater extent of volume expansion with reversibility. All of these considerations point to improved cycle life. Dimov et al. ${ }^{[27]}$ reported that SBR and CMC content are the most influential parameters for the improved cycle life of Si/C electrodes. It is clear that $\mathrm{CMC} \times \mathrm{SBR}$ has a favorable influence on the cycle life probably due to the increased strength of the electrode film.

In this study, Si and graphite are used as the active material through solid mixing, while water-based SBR and $\mathrm{CMC}$ are used as the binder to make high performance anodes. The procedure is easy to follow and avoids the usage of organic solvents, with water as the only media in the battery fabrication process, which is environmental friendly and cost saving.

\section{Experimental}

\subsection{Materials}

Styrene-butadiene rubber (SBR) emulsions (JSR Corporation, Japan), SBR 1: JSR SX8684(A)-64 (41.3\%, w.t.), SBR 2: JSR S2910(J)-17(26.4\%, w.t.), SBR 3: JSR TRD105A(40.7\%, w.t.). Carboxymethyl cellulose, sodium salt (CMC) (Aldrich), Mw 250000, D. S. 0.90. The 4\% (w.t.) CMC solution was made by dissolving $4 \mathrm{~g}$ CMC in $96 \mathrm{~g}$ deionized water. Conductive Carbon Black: TIMCAL SUPER C45. Si nanoparticles (50-70 $\mathrm{nm}$ ) are commercially available from Sigma-Aldrich. Si micro-particles are available from Argonne National Laboratory (ANL). Graphite: Hitachi magE. Composite Graphite (Conoco Phillips): CGP-G8.

\subsection{Slurry and electrode casting}

Graphite, silicon particles and conductive black were first mixed and milled in an agate mortar for 15 minutes. Then the CMC solution was added and milled for another 15 minutes. Finally, SBR emulsion and deionized water were added to the mixture and milled for 15 minutes. The mixture slurry was casted into thin film on copper foil by a $150 \mu \mathrm{m}$ thick blade. The films were first dried in room temperature for $3 \mathrm{~h}$ and then further dried at $60^{\circ} \mathrm{C}$ under $10^{-2}$ Torr pressure for $24 \mathrm{~h}$. The electrodes were compressed to around $40 \mu \mathrm{m}$ thick using a rolling mill.

\subsection{Coin cell fabrication and testing}

The electrodes were fabricated into standard 2325 coin cells with lithium film as counter electrodes done in an argon-filled glove box. A mixture of 70\% $1.2 \mathrm{M} \mathrm{LiPF}_{6}$ in EC: DEC (3:7 weight ratio) and $30 \%$ FEC was added as electrolyte. The coin cell performance was evaluated in a thermal chamber at $30^{\circ} \mathrm{C}$ with a Maccor Battery Test System. Cycling procedure includes two formation cycles of $C / 25$, followed by $\mathrm{C} / 10$ or $\mathrm{C} / 3$ cycles. 


\section{Results and discussion.}

\subsection{The optimized ratio of CMC and SBR}

Figure 1 shows the cycling performance of anodes made with different ratio of $C M C$ and $S B R$ as the binder under $\mathrm{C} / 10(1 \mathrm{C}=1 \mathrm{~mA} / \mathrm{g})$. The formulation of the anodes was CGP-G8 (Graphite)/Si (microsize) $/ C 45 /$ binder $=73 / 15 / 2 / 10$ (w.t. \%). While the total mass of binder accounts for $10 \%$ of the electrode mass, the ratio of CMC and JSR1 ranged from $0 / 10$ to $10 / 0$. The results of the electrode made with 0/10 ratio of $C M C$ and SBR are not showed in the figure because of failed electrode thin film coating on the copper foil. All the electrodes show fast capacity fading in the first 20 cycles and then slow down. The results indicate that as the ratio of $\mathrm{CMC}$ in the binder increases, the cycling performance of the electrodes increases at first, and then drops when further increases the ratio of $\mathrm{CMC}$. Overall, the electrode made with CMC/JSR1 $=4 / 6$ shows the best performance, indicating that the optimized ratio of CMC and SBR occurs at around 4/6. It is probably due to that a balance need to be reached between the adhesion force, which is provided by the $C M C$, and the elasticity, which is provided by the SBR, to improve the reversible capacity of Si containing materials during cycling ${ }^{[17,25]}$. The peel test results (Figure 2) show that all the electrodes show strong adhesion force, indicating the combination of CMC and SBR can adhesively bind the Si and graphite materials together in the electrode integrity, which is crucial to improve the cycling stability. 


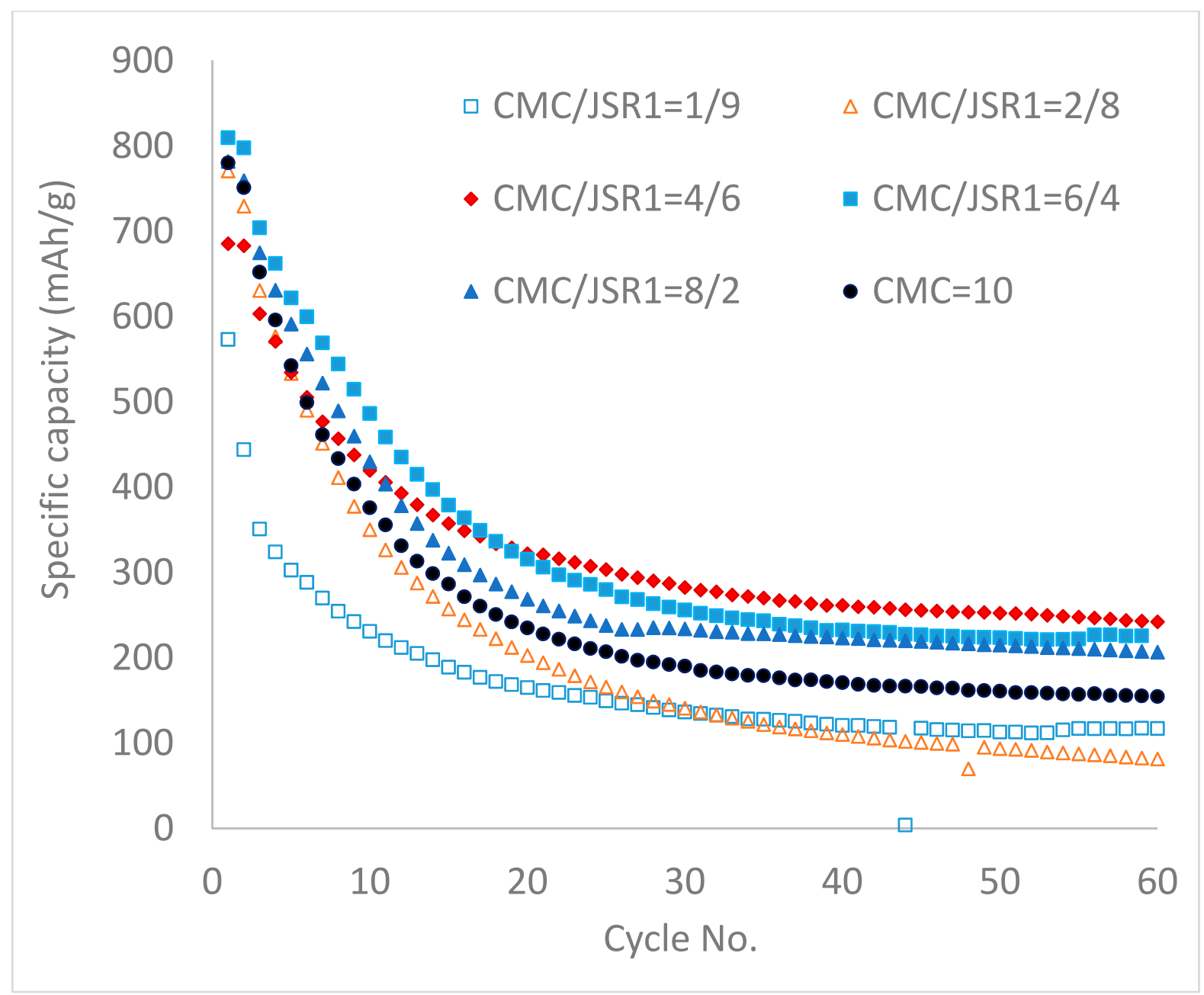

Figure 1. Cycle performance of anodes made of different binder ratio between CMC and SBR under C/10 


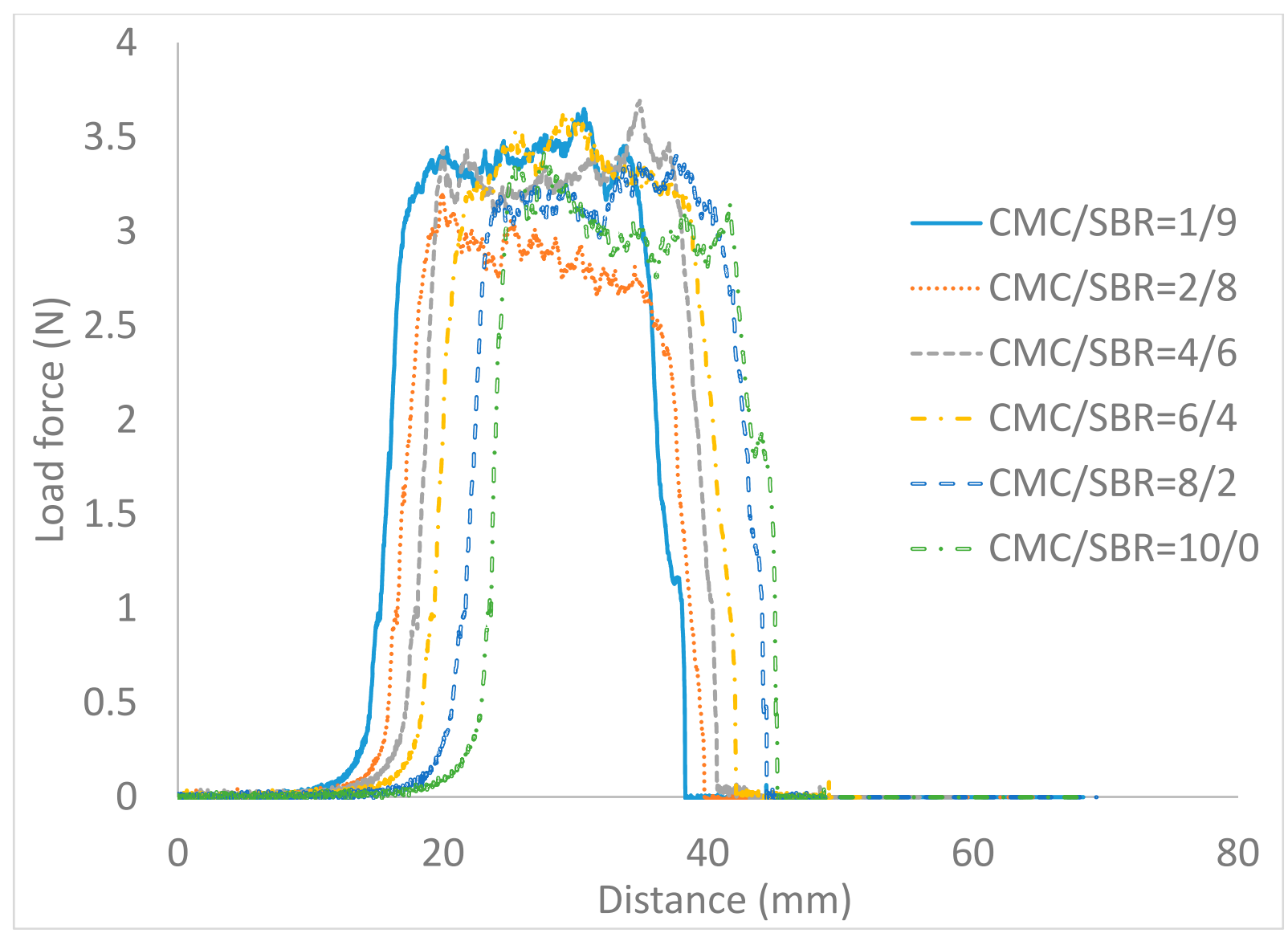

Figure 2. Peel test results of anodes made of different binder ratio between CMC and SBR

3.2 The electrochemical performance of micro-size and nano-size silicon particles.

The size of silicon particle plays an important role in the cycling stability of anodes. ${ }^{[22-24,28-31]}$ In order to investigate the size effect of silicon, two types of silicon, micro-sized and nano-sized, are fabricated into electrodes for electrochemical study. To simplify the electrode design, only $\mathrm{CMC}$ is used as the binder. The cycle performance testing is under $\mathrm{C} / 10(1 \mathrm{C}=1 \mathrm{~mA} / \mathrm{g})$. As shown in Figure 3 , though the $1^{\text {st }}$ cycle specific capacity is close to $800 \mathrm{mAh} / \mathrm{g}$, the micro-sized Si shows a fast capacity decay with limited capacity retention after 80 cycles at around $150 \mathrm{mAh} / \mathrm{g}$. In comparison, the nano-sized Si shows similar $1^{\text {st }}$ cycle capacities at about $750 \mathrm{mAh} / \mathrm{g}$ and stabilizes after 15 cycles at about $500 \mathrm{mAh} / \mathrm{g}$, which is retained even after 80 cycles. The nano-sized Si shows better capacity retention, probably due to that it enables higher intercalation/deintercalation rates, and the volume change can be buffered after downsizing the Si particles to nano-size ${ }^{[15]}$. 


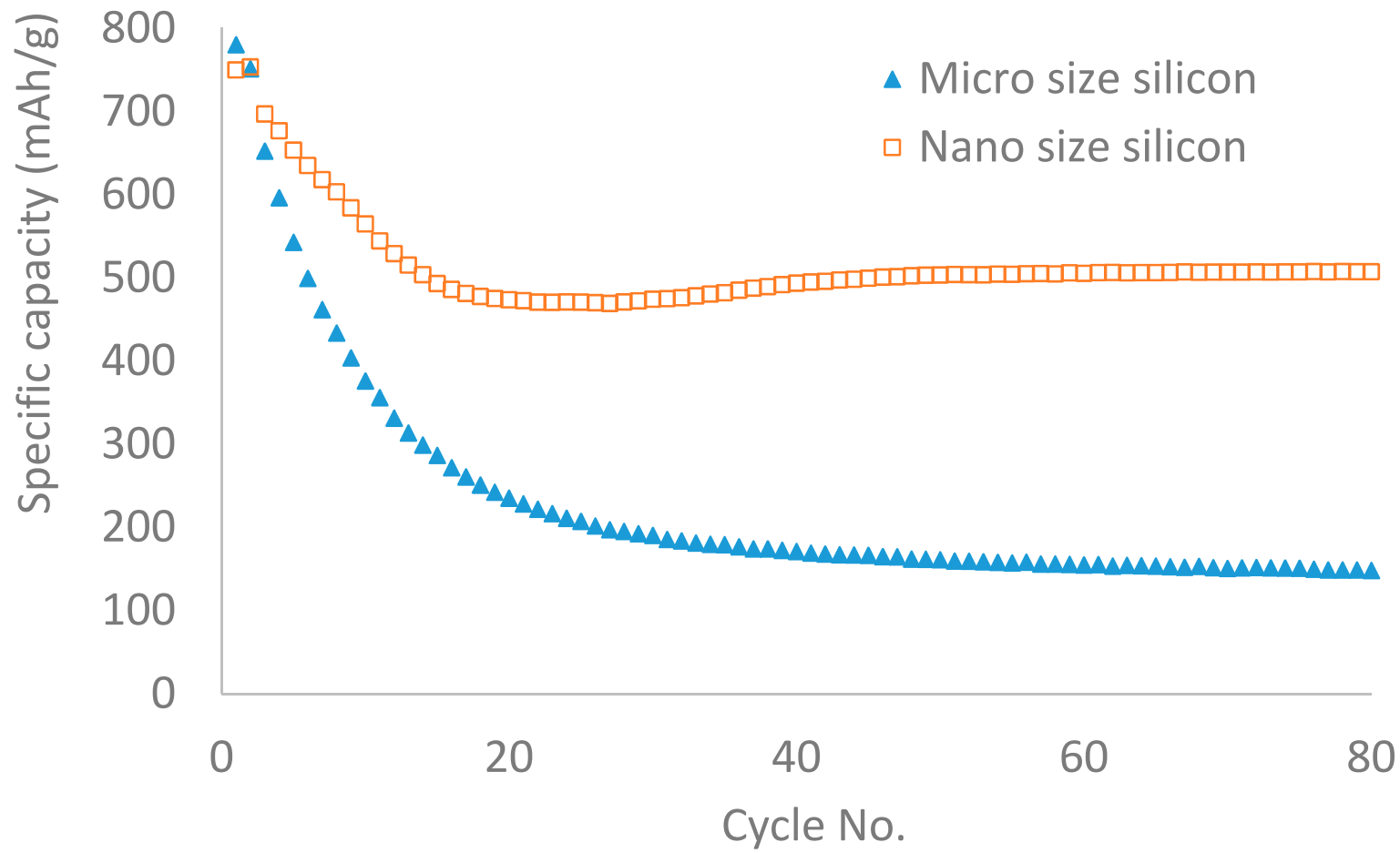

Figure 3. Cycle performance of micro-size and nano-size silicon/graphite composite anode

3.3 The effect of graphite to the performance of Si/C composite anode under C/10

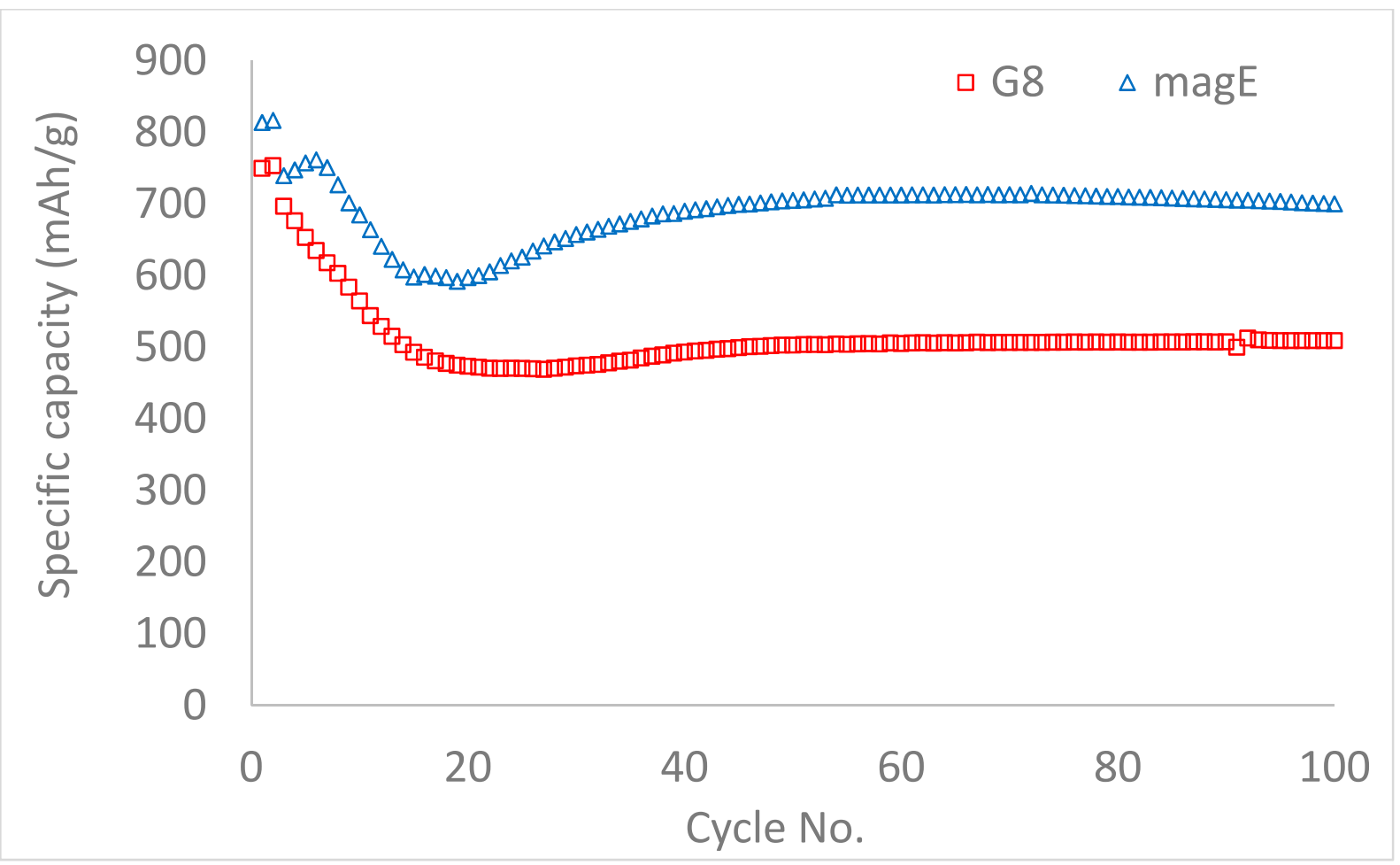

Figure 4 . The effect of graphite to the performance of Si/C composite anode under $\mathrm{C} / 10$ 
Two kinds of graphite (CGP-G8 and magE) were used to investigate the effect of graphite on the cycle performance of anode. CGP-G8 is composite graphite which was chose as baseline graphite for BATT program ${ }^{[32]}$ and magE is artificial graphite with many internal pores. The cycle performance of the anodes with different graphite under $\mathrm{C} / 10(1 \mathrm{C}=1 \mathrm{~mA} / \mathrm{g})$ is illustrated in Figure 4 . It can be seen that the $1^{\text {st }}$ cycle specific capacities of the anodes made from CGP-G8 and magE are 749.8 and $813.7 \mathrm{mAh} / \mathrm{g}$, respectively. Both electrodes experience an initial decay of performance in the first 20 cycles to reach a dip and then recover. The stabilized capacity for the electrode using CGP-G8 graphite is around 500 $\mathrm{mAh} / \mathrm{g}$ while that for the magE is around $700 \mathrm{mAh} / \mathrm{g}$. It indicates that using magE can achieve better cycle performance related to the different properties of CGP-G8 and magE.

3.4 The cycle of performance of Si/C composite anode using CMC and different SBR binder (or selection of different SBR binders)

Buqa et al ${ }^{[17]}$ reported that as low as $1-2 \%$ of SBR mixed with $1-2 \% \mathrm{Na}-\mathrm{CMC}$ as a binder is sufficient to assure a good electrochemical performance of nano-silicon/graphite electrodes. It is consistent with the results shown in Figure 1, which indicates that the optimized ratio of CMC and SBR is around 4/6.

Keeping this ratio and using magE graphite and nano-sized $\mathrm{Si}$ as the active materials, it is able to test the performance of different types of SBR emulsions available, which could be different in composition thus the properties. Three types of SBR emulsions, JSR1, JSR2 and JSR3 are studied and the results are shown in Figure 5 and Figure 6. The peel test results are showed in Figure 7. The three electrodes show similar cycling trend with $1^{\text {st }}$ cycle specific capacities between 610 to $680 \mathrm{mAh} / \mathrm{g}$ and the $1^{\text {st }}$ cycle coulombic efficiency are all higher than $88 \%$, comparable to pure graphite anodes ${ }^{[32]}$. After initial decay in the first 20 cycles, the three electrodes are able to cycle stably for 400 cycles, when the capacities are still retained at more than $500 \mathrm{mAh} / \mathrm{g}$ and the coulombic efficiency reaches $99.5 \%$. Overall, the electrode with JSR2 shows slightly lower capacity than that of JSR1 and JSR3, which may be explained by its lowest adhesion force among the three electrodes, as indicated in Figure 7. 


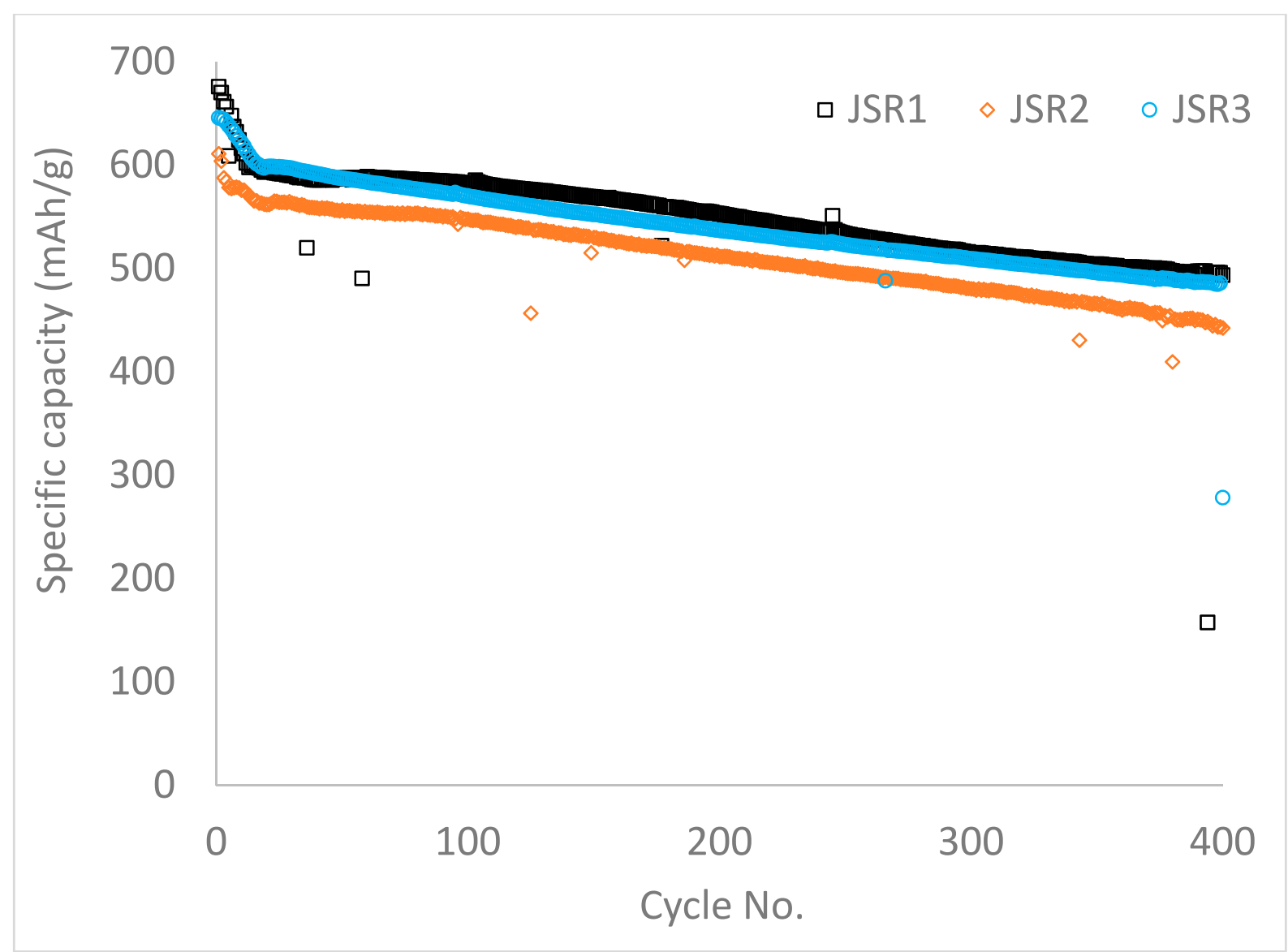

Figure 5. The cycle of performance of Si/C composite anode using different SBR binders under $\mathrm{C} / 3$ $(1 \mathrm{C}=0.75 \mathrm{~mA} / \mathrm{g})$ with constant voltage during each discharge step 


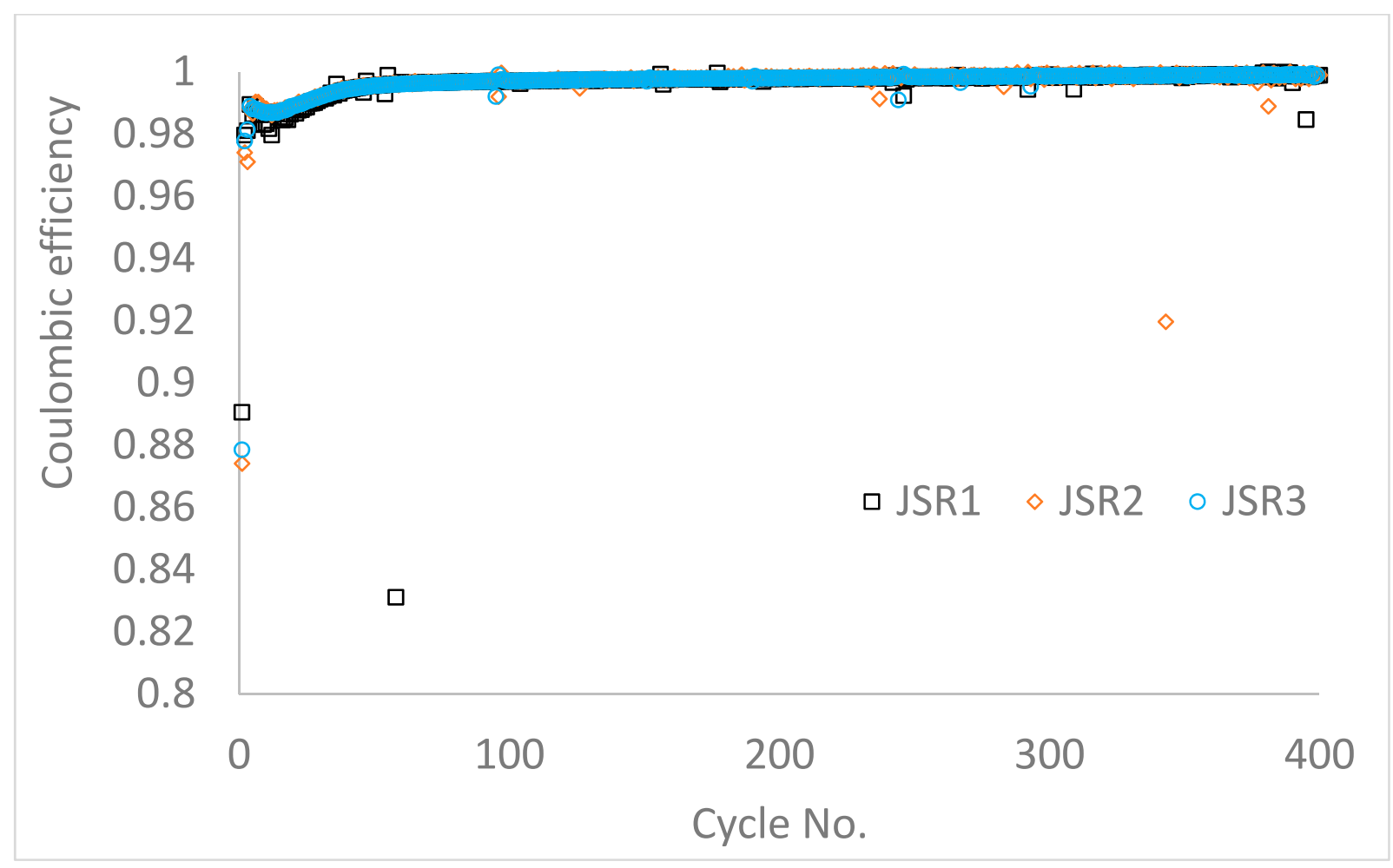

Figure 6. The coulombic efficiency of Si/C composite anode using both CMC and SBR as binder under C/3 $(1 \mathrm{C}=0.75 \mathrm{~mA} / \mathrm{g})$ constant voltage discharge and charge mode

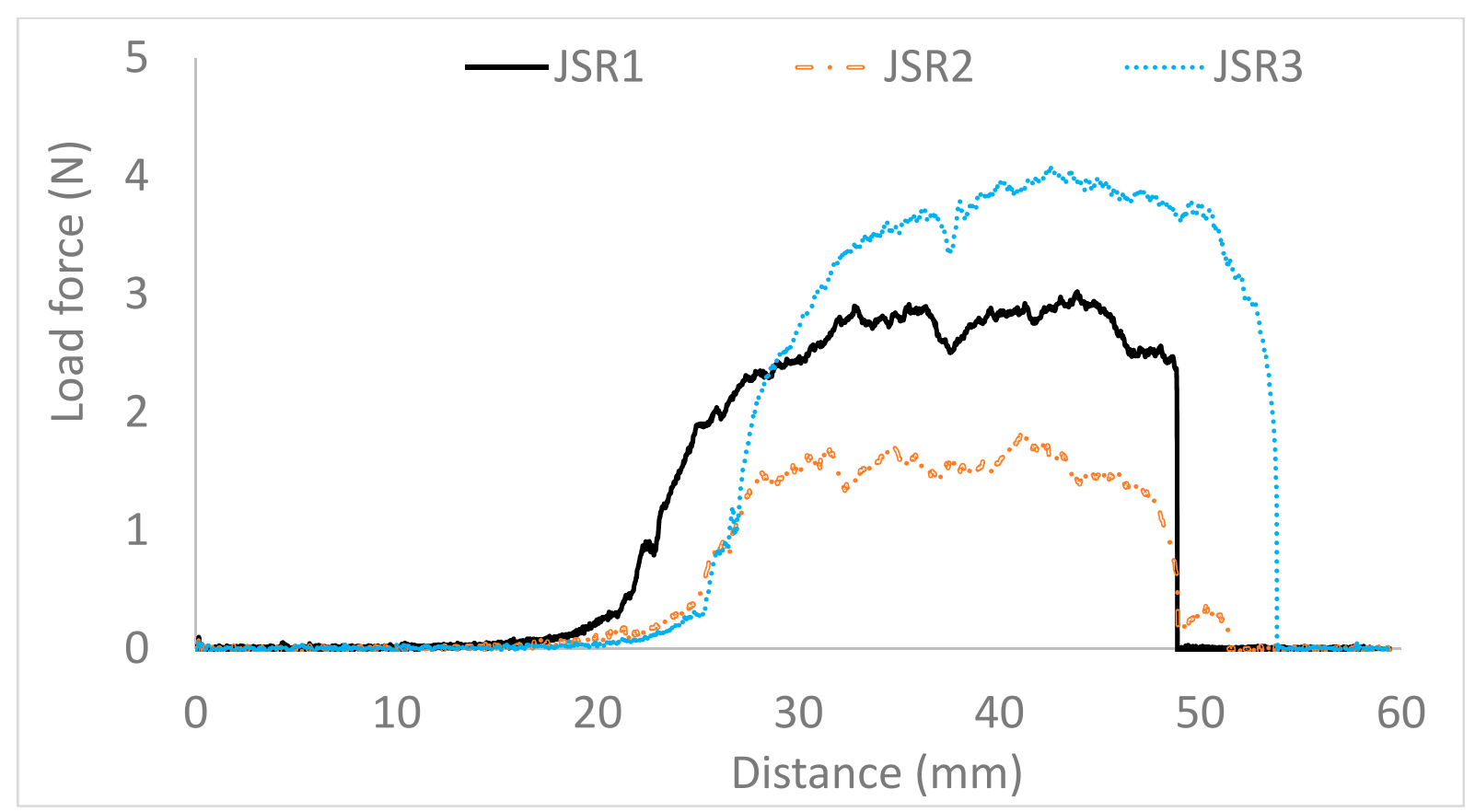

Figure 7. Peer test results of anodes made of different SBR binder (JSR1, JSR2 and JSR3) 3.5 Physical property changes of the Si/C composite electrodes after cycling 

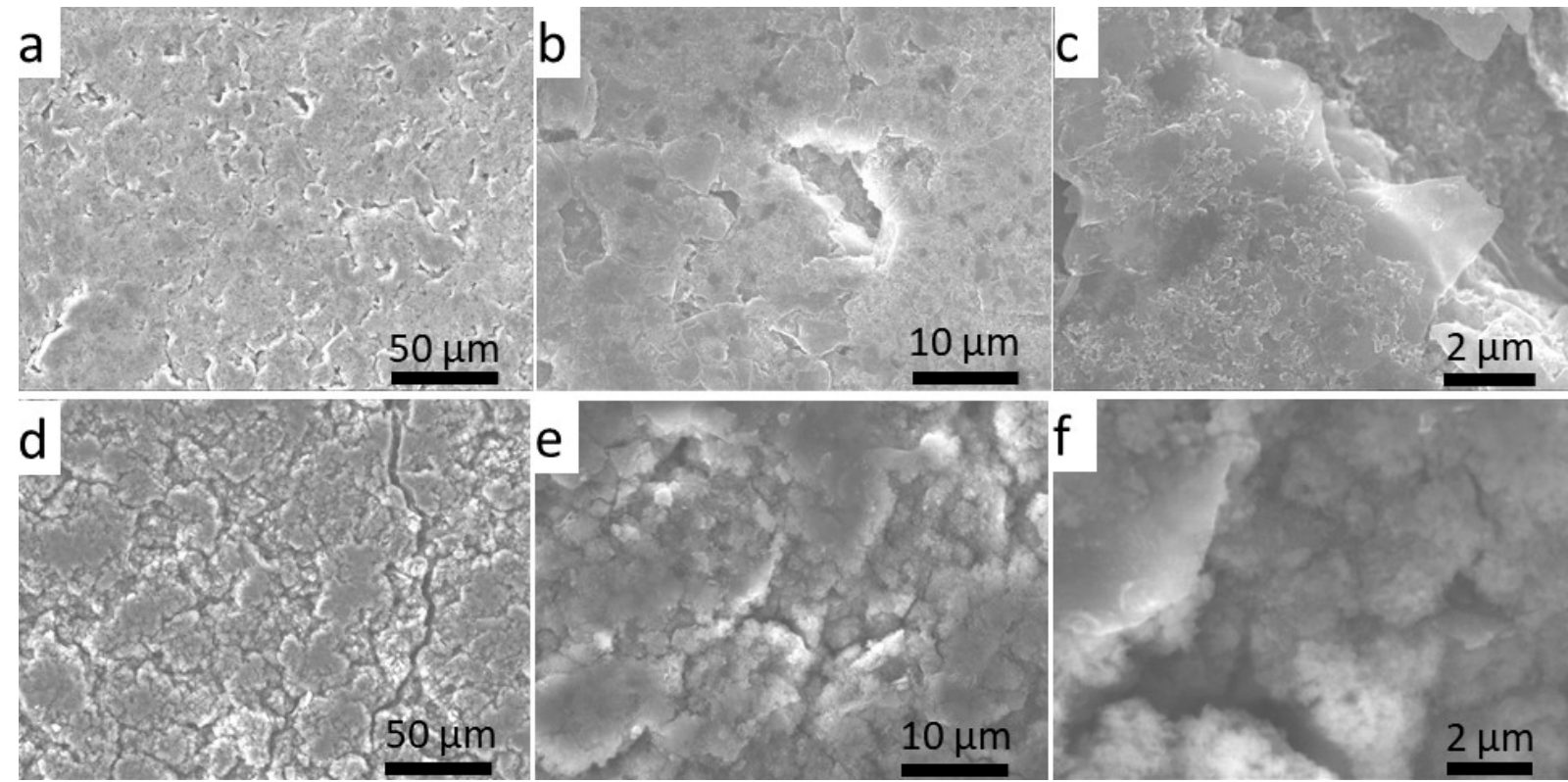

Figure 8. Physical properties of the $\mathrm{Si} / \mathrm{C}$ composite electrodes. The formulation of the anodes was magE/nanoSi/C45/CMC/JSR3=82.9/9.2/2.5/3/2.4 (w.t. \%). a, b, c: The SEM images of the anode before cycling. $d, e, f$ : The SEM images of the anode after cycling.

It can be seen (Figure 8, $a$ and $b$ ) that before cycling the surface of the electrode is smooth and tidy, and the active particles are firmly combined. There are many conductive particles distributed on the surface of active particles and the surface of the active particles is smooth and the edge is sharp before cycling (Figure $8, c$ ). However, there are many cracks on the surface of the electrode (Figure $8, d$ ) and there are gaps between active particles (Figure $8, \mathrm{e}$ ) after cycling. There are much less conductive particles on the active particles and the surface of the active particles is rough and the edge of the active particles is fuzzy after cycling (Figure 8, f). All these features may make the conductive of the anode worse, which maybe is one of the main factors that cause the specific capacity fade.

\section{Conclusion}

The binder material is one of the most crucial electrode components for improved cell performance ${ }^{[15]}$. In this paper, we studied the effects of binders on the cycle performance of the anodes. The results indicate that using a combination of $C M C$ and SBR can achieve better cycle performance than only using $\mathrm{CMC}$ as a binder. The optimized ratio of $\mathrm{CMC}$ and $\mathrm{SBR}$ is $4 / 6$ and $6 / 4$. We also found that decreasing the size of Si from mico-size to nano-size can significantly improve the cycle performance of the $\mathrm{Si} / \mathrm{C}$ composite anodes. The substitution of graphite CGP-G8 with magE can also improve the reversible capacities of the $\mathrm{Si} / \mathrm{C}$ composite anodes. At last, three high performance anodes were made by using graphite magE, nano-Si, conductive additive $\mathrm{C} 45$, and $\mathrm{CMC} / \mathrm{SBR}$. The battery fabrication process is simple and environmentally friendly. 


\section{Acknowledgment}

This research is funded by the Youth Talents Foundation of Chinese Academe of Inspection of Quarantine. This work is also funded by the Assistant Secretary for Energy Efficiency, Vehicle Technologies Office of the U.S. Department of Energy, under the Silicon Consortium Program. Electron microscopy experiments were conducted at the Molecular Foundry, which is located at Lawrence Berkeley National Laboratory (LBNL), and is supported by the Director, Office of Science, Office of Basic Energy Sciences, of the US Department of Energy under contract no. DE-AC02-05CH11231.

Author Contributions: Tianyue Zheng and Gao Liu conceived and designed the experiments; Haiqing Xiao performed the experiments and analyzed the data; Haiqing Xiao and Tianyue Zheng wrote the paper.

Conflicts of Interest: The authors declare that they have no conflict of interest.

\section{References}

1. Armand, M.; Tarascon, J.-M.; Building Better Batteries, Nature, 2008, 451: 652- 657.

2. Hassoun, J.; Panero, S.; Reale, P.; Scrosati, B.; A New, Safe, High-Rate, and High-Energy Polymer Lithium-Ion Battery, Adv. Mater. 2009, 21: 4807- 4810

3. Choi, J.; Kim, K.; Jeong, J.; Cho, K. Y.; Ryou, M.-H.; and Lee, Y. M.; Highly Adhesive and Soluble Copolyimide Binder: Improving the Long-Term Cycle Life of Silicon Anodes in Lithium-Ion Batteries, Appl. Mater. Interfaces, 2015, 7 (27): 14851-14858

4. Park, S.-J.; Zhao, H.; Ai, G.; Wang, C.; Song, X. Y.; Yuca, N.; Battaglia, V. S.; Yang, W. L.; and Liu, G.; SideChain conducting and phase-separated polymeric binders for high-performance silicon anodes in lithium-ion batteries, Journal of the American Chemical Society, 2015, 137: 2565-2571.

5. Goodenough, J. B.; Kim, Y.; Challenges for rechargeable Li batteries, Chem. Mater., 2010, 22 (3): 587603.

6. Choi, N.-S.; Chen, Z. H.; Freunberger, S. A.; Ji, X. L.; Sun, Y. K.; Amine, K.; Yushin, G.; Nazar, L. F.; Cho, J.; and Bruce, Challenges, P. G.; Facing Lithium Batteries and Electrical Double-Layer Capacitors, Angew. Chem., Int. Ed. 2012, 51 (40): 9994-10024.

7. Boukamp, B. A.; Lesh, G. C.; Huggin, R. A.; All-Solid Lithium Electrodes with Mixed-Conductor Matrix, J. Electrochem. Soc., 1981, 128 (4): 725-729.

8. Li, J.; Dahn, J. R.; An in Situ X-Ray Diffraction Study of the Reaction of Li with Crystalline Si, J. Electrochem. Soc. 2007,154 (3): A156-A161.

9. Ryu, J. H.; Kim, J. W.; Sung, Y.-E.; and Oh, S. M.; Failure Modes of Silicon Powder Negative Electrode in Lithium Secondary Batteries, Electrochem. Solid-State Lett. 2004, 7(10): A306-A309.

10. Christensen, J.; Newman, J.; Stress generation and fracture in lithium insertion materials, J. Solid State Electrochem., 2006, 10 (5): 293-319. 
11. Feng, X. J.; Yang, J.; Yu, X. L.; Wang, J. L.; Nuli, Y.; Low-cost SiO-based anode using green binders for lithium ion batteries, J. Solid State Electrochem., 2013, 17 : 2461-2469.

12. Chen, Y.; Zeng, S. Qian, J. F.; Wang, Y. D.; Cao, Y. L.; Yang, H. X.; Ai, X. P.; Li+-Conductive PolymerEmbedded Nano-Si Particles as Anode Material for Advanced Li-ion Batteries, Appl. Mater. Interfaces, 2014, 6 (5): 3508-3512.

13. Kamali, A. R.; Fray, D. J.; Review on Carbon and Silicon Based Materials as Anode Materials for Lithium Ion Batteries, J. New Mat. Electrochem. Systems, 2010, 13: 147-160.

14. Jung, D. S.; Hwang, T. H.; Park, S. B.; Choi, J. W.; Spray Drying Method for Large-Scale and HighPerformance Silicon Negative Electrodes in Li-lon Batteries, Nano Lett., 2013, 13 (5): 2092-2097.

15. Chou, S.-L.; Pan, Y. D.; Wang, J.-Z.; Liu, H.-K.; Dou, S.-X.; Small things make a big difference: binder effects on the performance of Li and Na batteries, Phys. Chem. Chem. Phys., 2014, 16: 20347-20359.

16. Yen, J.-P.; Chang, C.-C.; Lin, Y.-R.; Shen, S.-T.; Hong, J.-L.; Effects of Styrene-Butadiene Rubber/Carboxymethyl cellulose (SBR/CMC) and Polyvinylidene Difluoride (PVDF) Binders on Low Temperature Lithium Ion Batteries, J. Electrochem. Soc., 2013, 160 (10): A1811-A1818.

17. Buqa, H.; Holzapfel, M.; Krumeich, F.; Veit, C.; NováK, P.; Study of styrene butadiene rubber and sodium methyl cellulose as binder for negative electrodes in lithium-ion batteries, J. Power Sources, 2006, 161: 617-622.

18. Chen, L.B.; Xie, X. H.; Xie, J. Y.; Wang, K.; Yang, J.; Binder effect on cycling performance of silicon/carbon composite anodes for lithium ion batteries, J. Appl. Electrochem., 2006, 36 (10): 10991104.

19. Lestrie, B.; Bahri, S.; Sandu, I.; Roue, L.; Guyomard, D.; On the binding mechanism of CMC in Si negative electrodes for Li-ion batteries, Electrochem. Commun. 2007, 9 (12): 2801-2806.

20. Li, J.; Lewis, R. B.; Dahn, J. R.; Sodium Carboxymethyl Cellulose A Potential Binder for Si Negative Electrodes for Li-Ion Batteries, Electrochem. Solid-State Lett. 2007, 10 (2): A17-A20.

21. Hochgatterer, N. S.; Schweiger, M. R.; Koller, S.; Raimann, P. R.; Wöhrle, T.; Wurm, C.; Winter, M.; Silicon/Graphite Composite Electrodes for High-Capacity Anodes: Influence of Binder Chemistry on Cycling Stability, Electrochem. Solid-State Lett., 2008, 11 (5): A76-A80.

22. Ding, N.; Xu, J.; Yao, Y. X.; Wegner, G.; Lieberwirth, I.; Chen, C. H.; Improvement of cyclability of Si as anode for Li-ion batteries, J. Power Sources, 2009, 192: 644-651

23. Bridel, J.-S.; Azaïs, T.; Morcrette, M.; Tarascon, J.-M.; Larcher, D.; Key Parameters Governing the Reversibility of Si/Carbon/CMC Electrodes for Li-Ion Batteries, Chem. Mater., 2010, 22 (3): 1229-1241.

24. Erk, C.; Brezesinski, T.; Sommer, H.; Schneider, R.; Janek, J.; Toward Silicon Anodes for NextGeneration Lithium Ion Batteries: A Comparative Performance Study of Various Polymer Binders and Silicon Nanopowders, Appl. Mater. Interfaces, 2013, 5 (15): 7299-7307.

25. Liu, W.-R.; Yang, M.-H.; Wu, H.-C.; Chiao, S. M.; Enhanced Cycle Life of Si Anode for Li-lon Batteries by Using Modified Elastomeric Binder, Electrochem. Solid-State Lett., 2005, 8(2): A100-A103. 
26. Choi, N.-S.; Ha, S.-Y.; Lee, Y. W.; Jang, J. Y.; Jeong, M.-H.; Shin, W. C.; Ue, M.; Recent Progress on Polymeric Binders for Silicon Anodes in Lithium-Ion Batteries, J. Electrochem. Sci. Technol., 2015, 6(2): 35-49.

27. Dimov, N.; Noguchi, H.; Yoshio, M.; A chemometric investigation of the effect of the process parameters on the performance of mixed Si/C electrodes, J. Power Sources, 2006, 156: 567-573.

28. Zuo, P. J.; Yang, W. G.; Cheng X. Q.; Yin, G. P.; Enhancement of the electrochemical performance of silicon/carbon composite material for lithium ion batteries, lonics, 2011, 17 (1): 87

29. Li, H.; Huang, X.; Chen, L.; Wu, Z.; Liang, Y.; A high capacity nano Si composite anode material for lithium rechargeable batteries. Electrochem. Solid-State Lett., 1999, 2 (11): 547-549.

30. Kim, H.; Seo, M.; Park, M.-H.; Cho, J.; A critical size of silicon nano-anodes for lithium rechargeable batteries, Angew. Chem. Int. Ed. 2010, 49 (12): 2146-2149.

31. Ma, D. L.; Cao, Z. Y.; Hu, A. M.; Si-Based Anode Materials for Li-Ion Batteries: A Mini Review, NanoMicro Lett., 2014, 6 (4): 347-358.

32. Zheng, H. H.; Ridgway, P.; Song, X. Y.; Xun, S. D.; Chong, J.; Liu, G.; Battaglia, V.; Comparison of Cycling Performance of Lithium Ion Cell Anode Graphites, ECS Transactions, 2011, 33 (29): 91-100. 